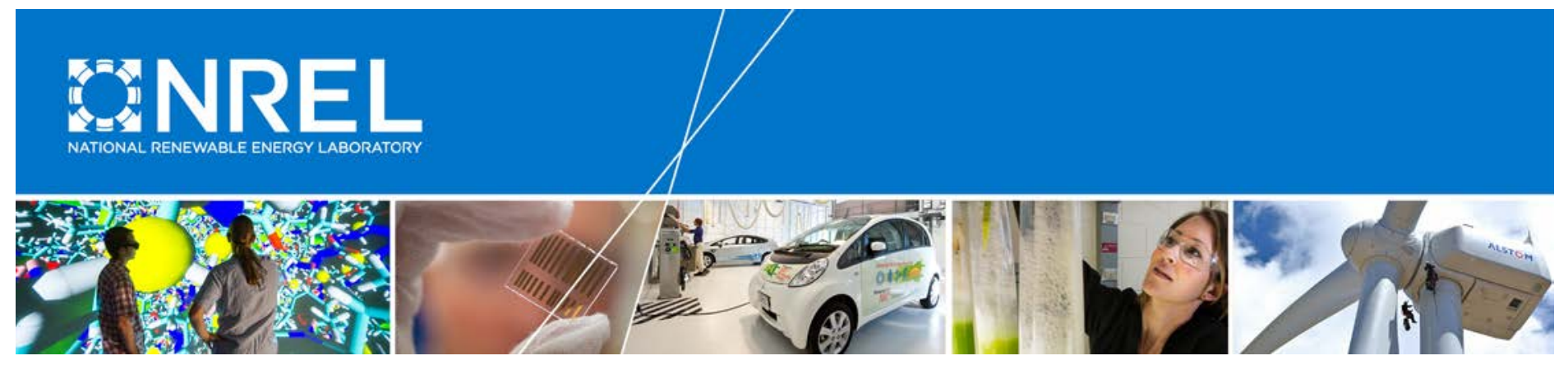

\title{
Integration, Validation, and Application of a PV Snow Coverage Model in SAM
}

David Severin Ryberg and Janine Freeman National Renewable Energy Laboratory

NREL is a national laboratory of the U.S. Department of Energy Office of Energy Efficiency \& Renewable Energy Operated by the Alliance for Sustainable Energy, LLC

This report is available at no cost from the National Renewable Energy Laboratory (NREL) at www.nrel.gov/publications.

Technical Report

NREL/TP-6A20-68705

August 2017 


\section{Integration, Validation, and Application of a PV Snow Coverage Model in SAM}

David Severin Ryberg and Janine Freeman National Renewable Energy Laboratory

Prepared under Task No. SETP-10304-11.01.20

NREL is a national laboratory of the U.S. Department of Energy Office of Energy Efficiency \& Renewable Energy Operated by the Alliance for Sustainable Energy, LLC

This report is available at no cost from the National Renewable Energy Laboratory (NREL) at www.nrel.gov/publications.

National Renewable Energy Laboratory 15013 Denver West Parkway Golden, CO 80401 303-275-3000 • www.nrel.gov

\section{Technical Report}

NREL/TP-6A20-68705

August 2017

Contract No. DE-AC36-08G028308 


\section{NOTICE}

This report was prepared as an account of work sponsored by an agency of the United States government. Neither the United States government nor any agency thereof, nor any of their employees, makes any warranty, express or implied, or assumes any legal liability or responsibility for the accuracy, completeness, or usefulness of any information, apparatus, product, or process disclosed, or represents that its use would not infringe privately owned rights. Reference herein to any specific commercial product, process, or service by trade name, trademark, manufacturer, or otherwise does not necessarily constitute or imply its endorsement, recommendation, or favoring by the United States government or any agency thereof. The views and opinions of authors expressed herein do not necessarily state or reflect those of the United States government or any agency thereof.

This report is available at no cost from the National Renewable Energy Laboratory (NREL) at www.nrel.gov/publications.

Available electronically at SciTech Connect http:/www.osti.gov/scitech

Available for a processing fee to U.S. Department of Energy and its contractors, in paper, from:

U.S. Department of Energy

Office of Scientific and Technical Information

P.O. Box 62

Oak Ridge, TN 37831-0062

OSTI http://www.osti.gov

Phone: 865.576 .8401

Fax: 865.576.5728

Email: reports@osti.gov

Available for sale to the public, in paper, from:

U.S. Department of Commerce

National Technical Information Service

5301 Shawnee Road

Alexandria, VA 22312

NTIS http://www.ntis.gov

Phone: 800.553 .6847 or 703.605 .6000

Fax: 703.605.6900

Email: orders@ntis.gov 


\section{Preface}

This paper serves as an update to an earlier paper by the same title published in September 2015. The original implementation of the snow model described in this paper in the System Advisor Model (SAM) had a bug that, when fixed, changed the results described herein. The bug reduces the amount of losses due to snow predicted in the national study, particularly in the northern part of the United States. Interestingly, however, the snow model after the bug was fixed shows less improvement for the verification systems than the snow model when it still included the bug; this fact, in conjunction with the fact that the losses predicted by the incorrect model were still within the range found in the literature, are likely why the bug went unnoticed in the original implementation. Many thanks to the diligent SAM users who, comparing the SAM implementation to Marion's original model, discovered, and reported the bug. 


\section{Abstract}

Due to the increasing deployment of PV systems in snowy climates, there is significant interest in a method capable of estimating PV losses resulting from snow coverage that has been verified for a variety of system designs and locations. Many independent snow coverage models have been developed over the last 15 years; however, there has been very little effort verifying these models beyond the system designs and locations on which they were based. Moreover, major PV modeling software products have not yet incorporated any of these models into their workflows. In response to this deficiency, we have integrated the methodology of the snow model developed in the paper by Marion et al. (2013) into the National Renewable Energy Laboratory's (NREL) System Advisor Model (SAM). In this work, we describe how the snow model is implemented in SAM and we discuss our demonstration of the model's effectiveness at reducing error in annual estimations for three PV arrays. Next, we use this new functionality in conjunction with a long term historical data set to estimate average snow losses across the United States for two typical PV system designs. The open availability of the snow loss estimation capability in SAM to the PV modeling community, coupled with our results of the nationwide study, will better equip the industry to accurately estimate PV energy production in areas affected by snowfall. 


\section{Table of Contents}

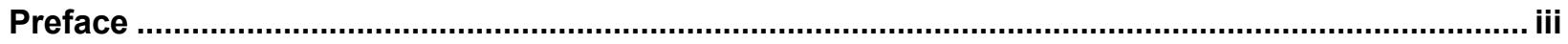

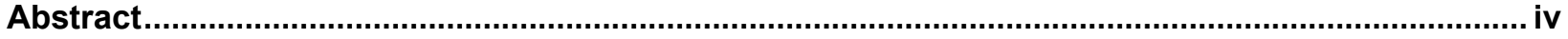

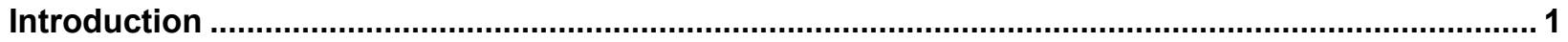

Implementation

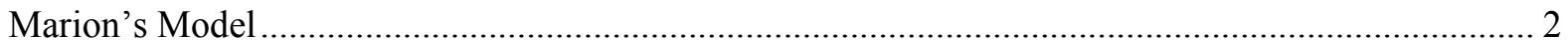

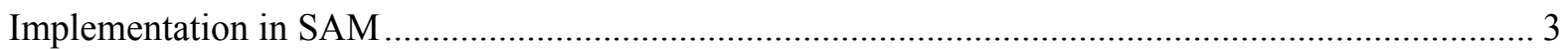

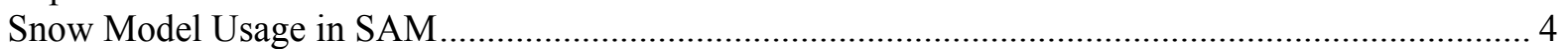

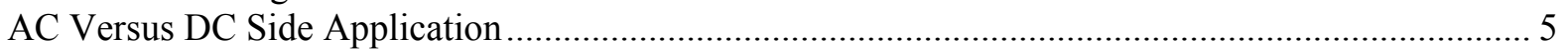

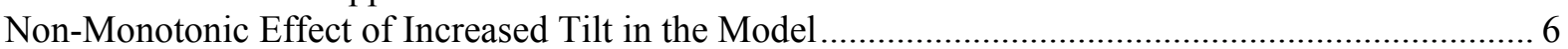

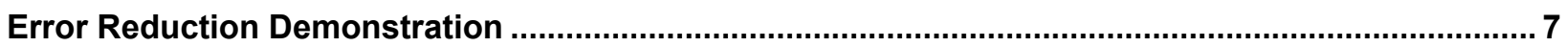

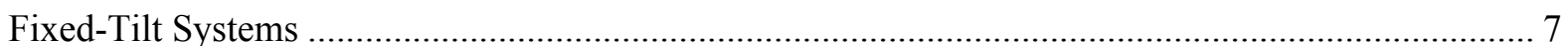

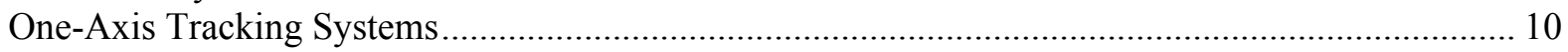

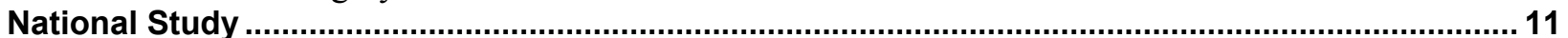

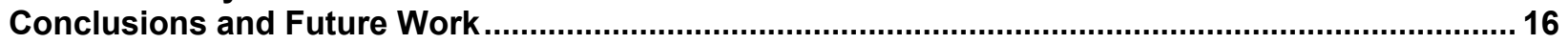

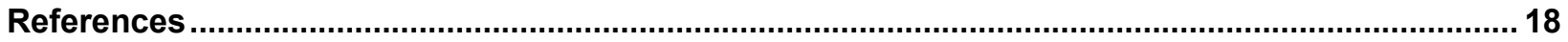

Appendix A. Tabulated Results from National Study...................................................................... 19

Appendix B. Full-Size Figures Showing General Trends in Average Snow Losses as a

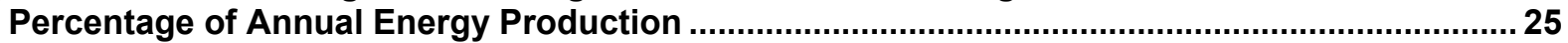




\section{List of Figures}

Figure 1. Simplified diagram of a PV array

Figure 2. An example system showing a non-monotonic decrease in annual snow losses with increased system tilt

Figure 3. Results from the validation study using the Forrestal system in Washington, D.C. and the RSF2 system in Golden, Colorado

Figure 5. Results from a national study modeling annual average PV production losses due to snow coverage using both a fixed-tilt-equals-latitude and a constant $20^{\circ}$-tilt system design, the historical TMY2 data set, and the newly implemented snow model in SAM

Figure 6. General trends in average snow losses as a percentage of annual energy production. Please see Appendix B for larger, shareable versions of these maps.

Figure 7. Correlation between the sum of the hourly snow depth array and the resulting percent loss for each year of each location in the tilt-equals-latitude national study .............................................. 15

Figure B-1. General trends in average snow losses as a percentage of annual energy production............. 26

\section{List of Tables}

Table 1. Monthly and Annual Errors With and Without Snow Model 9

Table A-1. Results from National Study 


\section{Introduction}

Snow coverage of PV systems and the associated losses in energy production have been recognized by the PV community as a significant loss that must be accounted for (Marion et al. 2013; Becker et al. 2006; Powers, Newmiller, and Townsend 2010; Andrews, Pollard, and Pearce 2013; Sugiura et al. 2003). However, the convoluted dynamics of snow coverage on PV systems (snow removal processes in particular), in addition to the large variability in determining a location's typical snowfall over the course of a year, have made a reliable model capable of estimating these losses infeasible for general use. Previous studies on this topic have measured losses in annual energy production ranging from 0\% (Andrews, Pollard, and Pearce 2013) to 25\% (Powers, Newmiller, and Townsend 2010). Of course, these studies vary substantially in terms of the type of the PV array employed and the physical location in which the study took place. Moreover, several empirical models have been developed by the community that can estimate these losses (Townsend and Powers 2011; Andrews and Pearce 2012); however, in almost all cases there has been little or no effort to verify these models beyond the systems on which their design was based. There is a clear need within the community for a model capable of reliably predicting PV snow losses for a variety of PV system types and in a variety of locations.

For this purpose, we have integrated the PV snow coverage model developed by Marion et al. (2013) into the National Renewable Energy Lab's (NREL) System Advisor Model (SAM). The following report details the methodology of the model's implementation, the results of a validation study against three PV systems that were not involved in the model's creation, and finally, the results of a national study using the new snow model in SAM. 


\section{Implementation}

\section{Marion's Model}

The PV snow coverage model in Marion et al. (2013) calculates the percentage of a PV array that will be covered by snow given daily snow depth measurements as well as hourly system tilt, plane of array (POA) irradiance, and temperature values. The model considers snow sliding to be the dominant removal process and therefore does not account for snow melting or wind removal (except in the case of flat fixed-tilt systems). Other works, independent of Marion's analysis, have also expressed snow sliding as a dominant removal process (Becker et al. 2006; Andrews, Pollard, and Pearce 2013; Sugiura et al. 2003). A brief description of the model is provided.

At the beginning of each day, the model checks to see if a snowfall has occurred during that day. If it has, the model assumes that the PV array being simulated will be completely covered by snow. If a new snowfall is not detected, the coverage is left at its value at the end of the previous day. For each hour in the day, the array will remain covered unless the plane of array incidence (the total amount of radiation incident on the PV module) and ambient temperature are sufficient to allow some of the accumulated snow to slide off the PV array. More specifically, snow sliding will only occur so long as the following inequality is satisfied:

$$
T_{a}>\frac{I_{\text {poa }}}{m}
$$

where $T_{a}$ represents the ambient temperature, $I_{\text {poa }}$ represents the plane of array irradiance, and $m$ represents Marion's empirically defined value $-80 \mathrm{~W} /\left(\mathrm{m}^{\wedge} 2{ }^{\circ} \mathrm{C}\right)$. If the model determines that sliding is possible during a particular hour, then the amount of the PV array that will be exposed in that hour, measured in tenths of a row's total height (see Figure 1), is a function of the PV system's tilt.

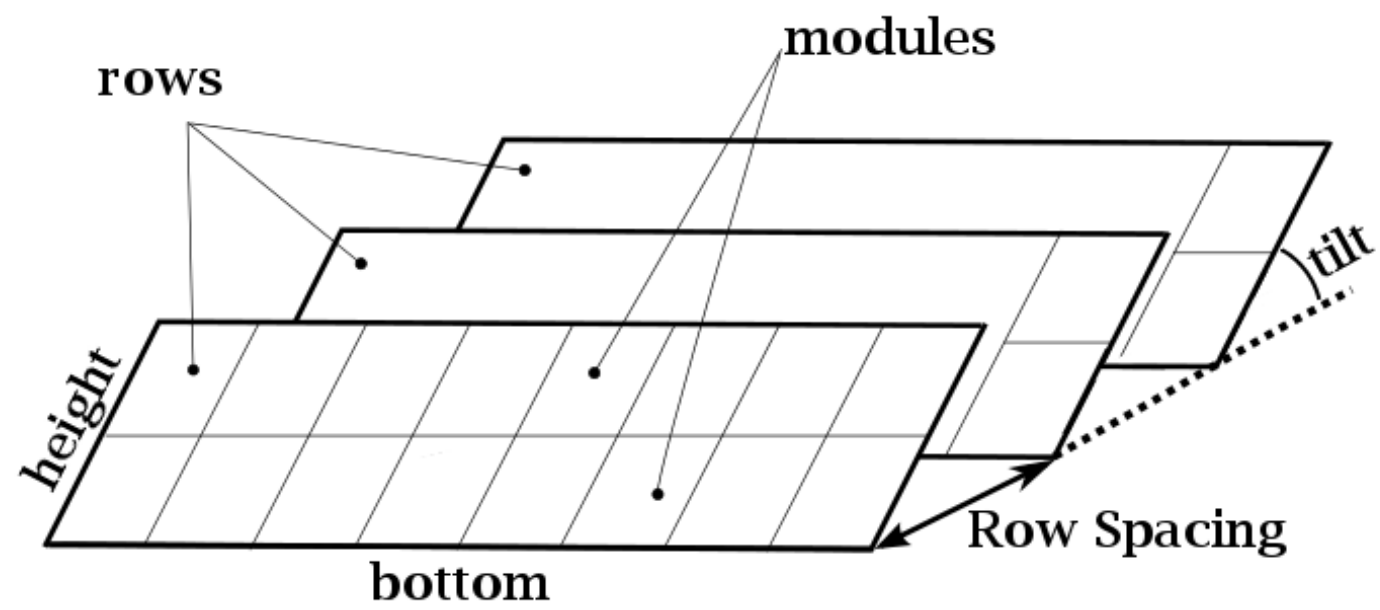

Figure 1. Simplified diagram of a PV array 
The amount that will be exposed, in tenths of total row height, can be found using:

$$
\text { Snow Slide Amount }=1.97 * \sin (\text { tilt })
$$

The 1.97 constant in this equation was experimentally determined by Marion et al. (2013) for roof-mounted systems and will be referred to as the sliding coefficient. At the end of the hour during which the calculation permits sliding, the initial PV snow coverage will be decremented by the snow slide amount. Finally, given the new height of snow relative to the PV row's height and the configuration of PV strings in a row, the number of PV strings within the system which are not covered with snow is determined. These modules are allowed to operate normally while the energy production of the others is set to zero. The model then moves on to the next hour in the day and repeats this process.

Marion et al. (2013) also provided a sliding coefficient for ground-mounted systems, which is reported as 6.0 tenths of PV row height per hour. The discrepancy between these two values stems from the necessity of roof mounted systems to account for snow accumulating at the lower edge of an array and preventing snow removal from the lower modules. To date, however, only the sliding coefficient for roof-mounted systems has been incorporated into SAM because it was determined from a larger sample size in Marion's analysis and therefore better validated.

\section{Implementation in SAM}

The final implementation of Marion et al.'s (2013) model in SAM is procedurally very similar to Marion's original model; however, there are a small number of differences that warrant discussion. Two of the changes were overrides that prevent illogical behavior. The first of these simply checks the snow coverage at the end of each time step and prevents the coverage from going below $0 \%$. Second, when calculating the snow coverage at the beginning of each time step, we included an additional check for zero snow depth at that time. We assume that if the snow depth at that time is zero, then the coverage percentage on the PV array should also be zero. This check accounts for zero-degree fixed-tilt PV arrays on which, in the original model, snow would never slide off once it had accumulated. This second check was not required in Marion's original model since that model was designed for system tilts between $10^{\circ}$ and $45^{\circ}$. However, as we will discuss in the validation section, with this override the implemented PV snow coverage model is also effective for flat systems.

Following this, by conducting a review of the currently available snow depth sensors, we found that many devices have an uncertainty between 0.5 and $1.0 \mathrm{~cm}$. Therefore we also included threshold values for minimum depth and minimum change in depth (delta), which are intended to filter out noise in the snow depth measurements and reduce spurious responses to data uncertainty, such as findings of new snowfall during summer months. We incorporated these thresholds within the portion of the implementation that determines whether a new snowfall has occurred. If the original model identifies a new snowfall but either the snow depth is less than the depth threshold or the change in snow depth (with respect to the previous time step's depth) is less than the delta threshold then we assume this is an erroneous detection and it is ignored. We set these thresholds equal to $1 \mathrm{~cm}$ for consistency with snow depth measurement uncertainties; an additional sensitivity analysis on these threshold values indicated that different depth threshold values within a range of 0.5 to $1.5 \mathrm{~cm}$ do not significantly affect estimated snow losses. 
Lastly, Marion's original model applied snow losses for an hourly simulation using a daily snow depth data set which was measured every day at 7am. However, SAM users may have access to more resolved snow depth data. Additionally, SAM is capable of simulating PV performance for sub-hourly time intervals. Therefore, it was necessary to adapt the snow model's implementation to allow for the usage of hourly and sub-hourly snow depth data sets as well as to accommodate sub-hourly simulations.

First, we sought to determine if the model would lose accuracy if the check for a new snowfall is performed hourly versus once a day. In order to compare the two methods fairly, we fabricated an hourly snow depth data set from a pre-existing daily data set by setting each hour in a single day to the snow depth record of the corresponding day in the daily set. Then, we executed the model in both its original daily form (including the changes discussed up until this point) and in another form that checks for a new snowfall at the start of each hour. We found that, as expected, the two methods produced identical results. Similarly, we conducted another study where we considered NREL's Research Support Facility 2 (RSF2) PV array, which has hourly measured power outputs and meteorological data, including hourly snow depth data. We converted the hourly snow depth data for this site to a daily data set (by setting all values in a day to the value at 7 a.m. in the hourly set in accordance with Marion's data collection procedure) and ran simulations in SAM with both sets. We found that the simulation with the hourly data set resulted in less error in annual energy compared to measured data than the simulation with the daily set. The method used to calculate these errors will be discussed further in the validation section. Because checking for a new snowfall at the beginning of hour as opposed to at the beginning of each day produced no difference when a daily snow depth data set was converted to an hourly set, and because the algorithm was shown to lose accuracy when the opposite conversion was performed, we decided to check for a new snowfall at the beginning of each time step for the final implementation.

Second, we accounted for sub-hourly calculations. The workflow of the snow model is unchanged with the exception that the sliding coefficient and the delta threshold, which were originally determined as hourly values, are both scaled by the inverse of the number of time steps in an hour. For example, if SAM is provided with 15-minute weather data, then the sliding coefficient and the delta threshold are each multiplied by 0.25 to convert them from hourly to 15 minute values.

\section{Snow Model Usage in SAM}

The resulting PV snow coverage model can be accessed in two separate ways: by running the model in conjunction with an ongoing PV simulation or by invoking the model after a complete PV simulation has occurred. In the desktop version of SAM, the snow model can be activated by navigating to the 'Shading and Snow' design page and selecting the 'Estimate losses due to snow' check box. Doing so will instruct the snow model to run in conjunction with the PV simulation and will logically be applied at the same point as similar losses (shading and soiling). In SAM's workflow this occurs after losses associated with the modules themselves (module efficiency and degradation) are applied, but before the inverter model is run. The same behavior can be achieved either through SAM's LK scripting language or in one of the SDK extension languages by setting the 'en_snow_model' variable to 1 ; its default value is 0 , which deactivates the snow model. Once the snow model is activated, a SAM PV simulation can be executed 
normally and the final power reports will reflect snow loss estimations. Moreover, time series arrays of the amount of energy lost in each subarray due to snow coverage can be accessed through the 'subarray $[n]$ snow_loss' variables, where $[n]$ is replaced with a specific subarray's identification number. For more information on how to use SAM's LK scripting language or access the SDK, visit the SAM webpage at sam.nrel.gov.

The second method of accessing the snow model - invoking the model after a simulation has occurred - can only be accomplished by using either SAM's LK scripting language or through the SDK. Additionally, invoking the snow model in this manner requires that a time series array of the modeled system's energy output be provided as an input to the snow model. This can be accomplished in one of two ways: One, by executing a full SAM PV simulation, without having activated the snow model, in which case the required output variable will already be present in the SAM instance, or, two, by manually providing an energy output array, through the method discussed in SAM's operating manual, and defining it as the 'gen' variable. The input 'gen' array can be either DC or AC energy, a fact which we will discuss next. Once invoked, the snow model will calculate loss estimates due to snow coverage at each time step and will deduct the appropriate losses from the initial energy time series. Regardless of when the snow model is applied, its success is dependent on the input weather file containing valid snow depth data.

\section{AC Versus DC Side Application}

Snow coverage on PV arrays immediately results in a decreased DC power output by the array, so it makes the most sense to apply the losses estimated by a snow model at the same time that similar losses (shading and soiling) are applied. The empirical correlations in Marion's model, however, were formulated using the measured $\mathrm{AC}$ power, so we examined whether the model is still valid when applied to the DC side of power conversion.

As discussed previously, the way in which the model was implemented into SAM allows for execution of the snow model either simultaneously with SAM's PV model workflowequivalent to applying snow losses on the DC side of power conversion - or independently after a SAM PV simulation has completed - equivalent to AC-side application. Fortunately, this made comparing the application of the model on either side a straightforward process. We ran a series of comparisons, each consisting of two simulations using identical system designs and weather files. One simulation included the snow model that ran during the SAM PV simulation (on the DC side) and the other simulation included the snow model that ran after the SAM PV simulation (on the AC side). In each case, the final annual energy values predicted by the two simulations were within approximately $2 \%$ of each other, which is within an acceptable error margin. This suggests that the side to which the snow model is applied is not of great importance. Nevertheless, users should be aware that slight differences are expected, particularly if they wish to post-process PV performance data obtained elsewhere using SAM's snow loss model. Unless otherwise specified, it should be assumed that the snow model was applied on the DC side for the remaining analyses discussed in this work. 


\section{Non-Monotonic Effect of Increased Tilt in the Model}

When using Marion's model as implemented in SAM, increasing the tilt of the system does not necessarily cause a monotonic decrease in annual snow loss percentage as it would be expected to in the real world (see Figure 2). This is due to the model's assumption that if a string is even partially covered by snow, it produces zero power, combined with the fact that the model is run at discrete time intervals. Let us assume that the time interval for a simulation is one hour. As tilt increases, the amount of snow that slides off of an array in a given hour also increases - but it must increase to a certain point before a new string is completely uncovered one hour sooner than at a lower tilt, and can produce power for that additional hour. Before that point, no additional power is produced, but additional plane-of-array irradiance strikes the array as a result of the increased tilt. Therefore, the amount of power lost due to snow actually increases until it hits the point where a new string is uncovered one hour sooner in a given snow event, and then snow loss decreases with a sudden jump. This effect becomes less pronounced as the number of modules along the side of a row (nmody) increases, as demonstrated by the three different lines in Figure 2, because fraction of snow that must slide to uncover a new string - and therefore how much time it takes for a new string to be uncovered-decreases with increasing numbers of strings in a row. This effect would also decrease if the time interval of the simulation were decreased. It is important to recognize that this is not a real-world phenomenon but rather a result of model assumptions and discrete time intervals.

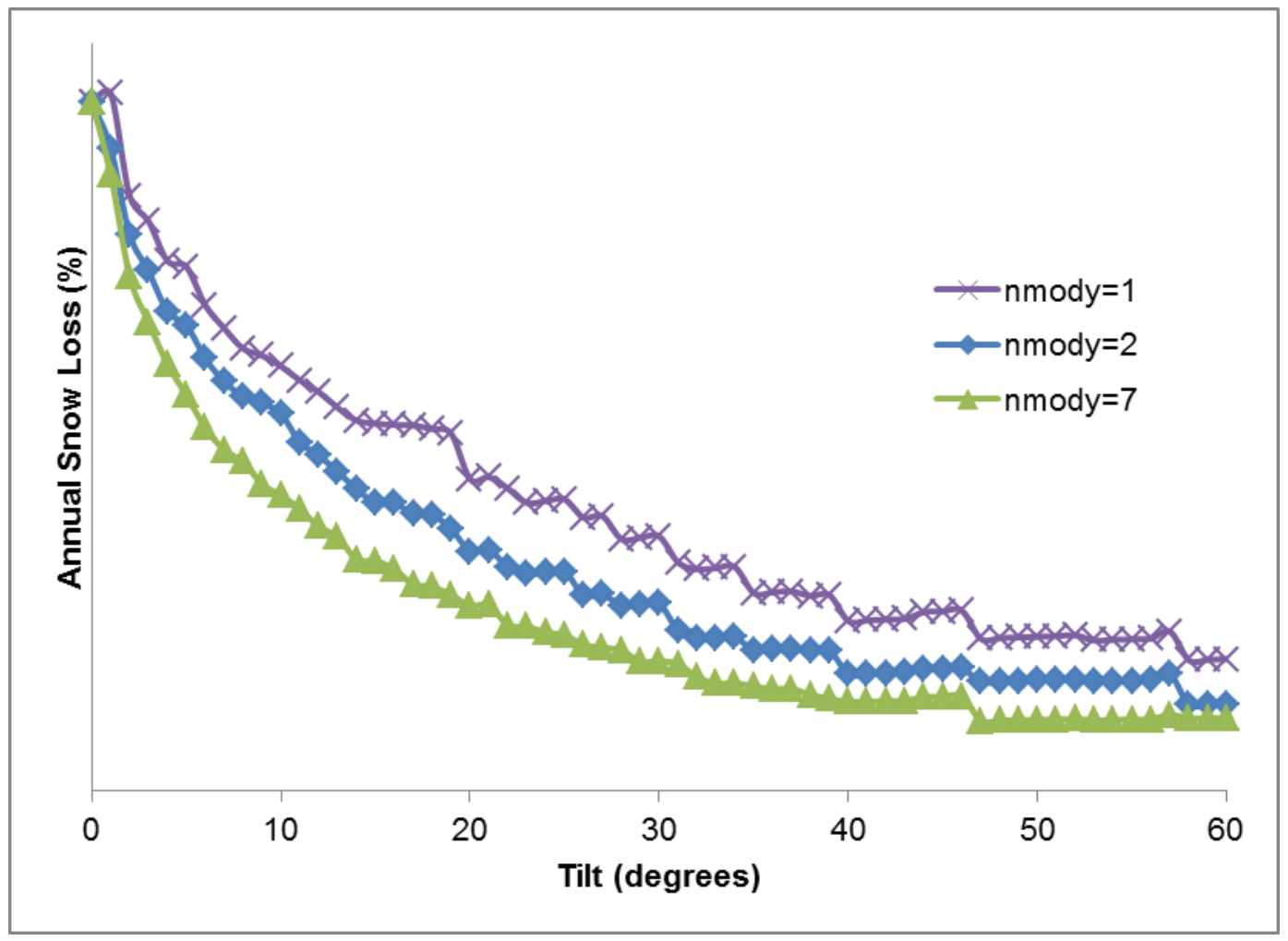

Figure 1. An example system showing a non-monotonic decrease in annual snow losses with increased system tilt

This is not a real-world phenomenon but rather a result of model assumptions and discrete time intervals. 


\section{Error Reduction Demonstration}

Snow models have been available to the PV industry for close to two decades; however, in most cases there has not been a large validation effort. User confidence in the conclusions reached using a snow model may increase with greater similarity between the user's system and the system, or systems, from which the snow model was developed. However this is not equivalent to systematic validation. Naturally, a complete validation of a snow model would require comparing simulation results to measured data sets for representatives of each type of system design in each type of weather climate - an effort which is far beyond the scope of this study even if such data sets existed. Nevertheless, in order to build confidence in the results reported by the PV snow coverage model implemented in SAM, we demonstrated the model's effectiveness in reducing the error in estimating annual energy production with respect to measured data for three systems. None of these validation systems played a role in Marion's original model's conception.

\section{Fixed-Tilt Systems}

Two of the systems that were used for validation were the Forrestal system, located on the James Forrestal Building in Washington, D.C., and the RSF2 system, located on NREL's Research Support Facility in Golden, Colorado. Both are fixed-tilt systems, with tilt angles of $0^{\circ}$ and $10^{\circ}$ respectively, that have previously been used as case studies for SAM validations. These validations showed good agreement with SAM predictions excluding system downtime and time periods with heavy snowfall (Freeman et al. 2013). The concurrent weather data and measured data for the two systems come from the same data set used in Freeman et al. (2013): Nov. 2009 Jul. 2010 for the Forrestal system and 2012 for the RSF2 system.

The results of the snow model validation study are shown in Figure 3. For each month in a year, the figure shows SAM's predicted energy output using the snow model in blue, the actual measured output of the system in green, and SAM's predicted energy output when not using the snow model in red. For months with snow, the number of hours within each month that have a snow coverage percentage above zero, with regards to the snow model simulation, is displayed above the bars. Each system had several days of down-time, measurement failure, or missing data. For instance, there are no measured data for the Forrestal system spanning the entire months of August, September, and October. The Forrestal system is also missing 7 days of data in mid-July as well as the first 13 days of November, which is why these months display less power output than would be expected during these times. The RSF2 system fares better in the sense that the measured data are only missing 38 days throughout the year. Twenty-two of these missing days occur in the month of July and the remaining 16 are distributed sporadically throughout the year. For our analysis, if the measured data were missing or were otherwise flagged as erroneous for a particular time period, then the simulated outputs for that time period were ignored and weren't factored into error calculations. 

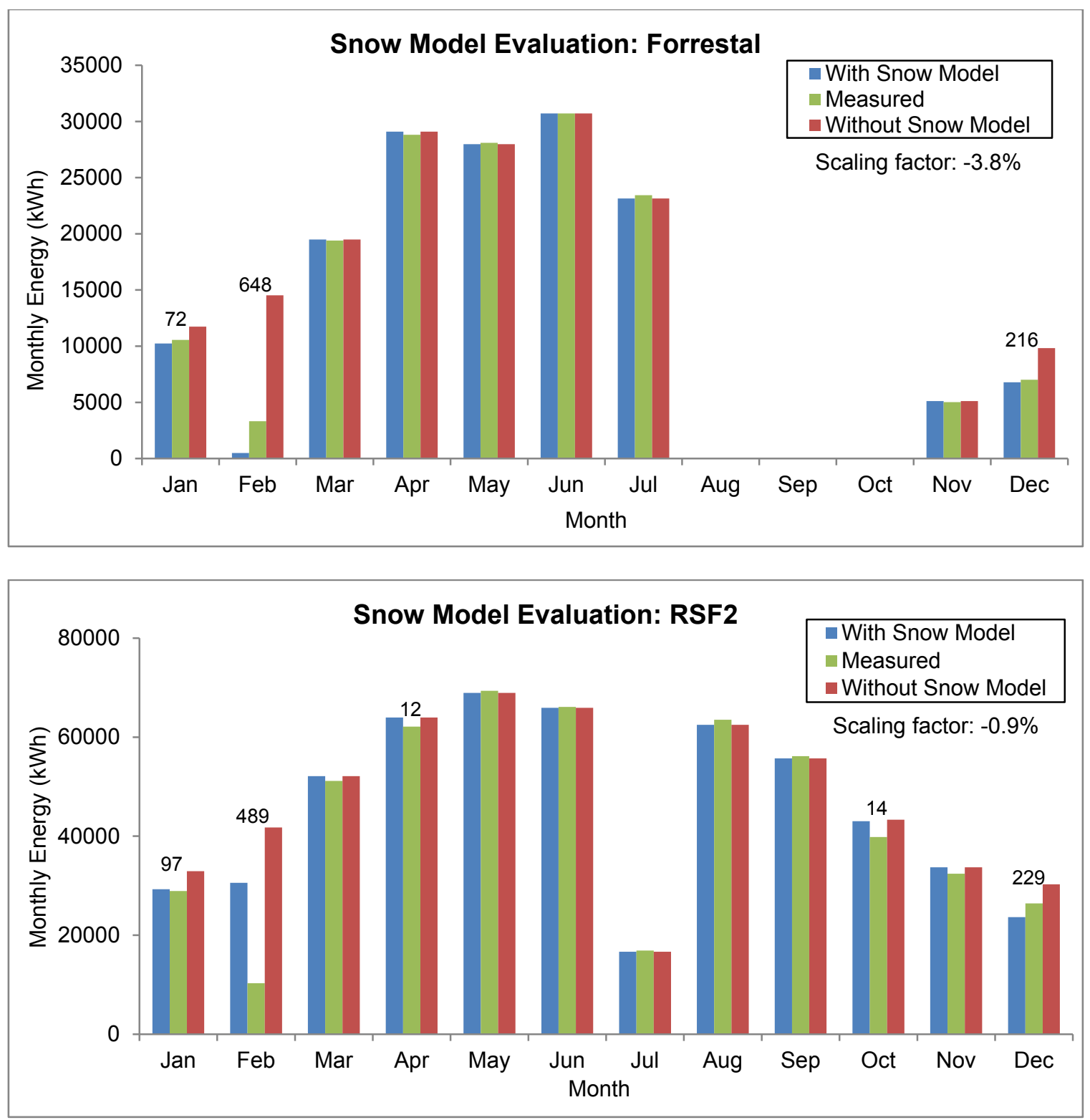

Figure 3. Results from the validation study using the Forrestal system in Washington, D.C. and the RSF2 system in Golden, Colorado 
Fortunately, very few of the missing days occur during the months with heaviest snowfall (January, February, and December). Before error calculations were made, however, a scaling factor was applied to the results of each simulation in order to provide the best fit to the measured data during the summer months (April - Aug) and these values are displayed in the top-left corner of each plot. This was done in order to help isolate any error changes which resulted from activating the snow model, rather than having this error skewed by systematic error that is present year-round. Table 1 displays the errors compared to measured data associated with each of the winter months, as well as the errors in total annual energy. Error calculations were performed using:

$$
\text { Error }=\frac{\text { Simulated }- \text { Measured }}{\text { Measured }} \times 100 \%
$$

Reductions in absolute error were also included in order to provide a sense of how changes in each particular month affected the total annual error. These values are calculated using:

$$
\text { Absolute Error Reduction }=\frac{(\mid \text { Without Model }|-| \text { With Model } \mid) * \text { Measured Monthly Energy }}{\text { Measured Annual Energy }}
$$

In Table 1, positive error values correspond to an over-prediction of the estimated energy production, while negative values indicate an under-prediction. A decrease in the absolute value of these error percentages, reported as a positive value in the 'Absolute Error Reduction' row, reflects an improvement in the simulation's annual prediction, because the estimated energy production with the snow model activated is closer to the measured production. In all cases, the snow model is observed to improve the absolute monthly error in estimated energy. For both systems, the month of February contributed most to annual error before the snow model was employed and likewise showed the largest improvement in energy production estimations. Most importantly, the snow model is observed to improve SAM's estimate in annual energy in both cases - from total annual error of $9.7 \%$ to $-2.2 \%$ for the Forrestal system and from $8.5 \%$ to $4.4 \%$ for the RSF2 system.

Table 1. Monthly and Annual Errors With and Without Snow Model

\begin{tabular}{ccrrrr} 
& & January & February & December & Annual \\
\hline \multirow{3}{*}{ Forrestal } & With Model (\%) & -3.1 & -85.1 & -3.2 & -2.2 \\
& Without Model (\%) & 11.1 & 336.8 & 40.2 & 9.7 \\
\cline { 2 - 6 } & Absolute Error Reduction (\%) & 0.5 & 5.4 & 1.7 & 7.5 \\
\hline \multirow{2}{*}{ RSF2 } & With Model (\%) & 1.3 & 197.4 & -10.6 & 4.4 \\
& Without Model (\%) & 13.9 & 306.1 & 14.5 & 8.5 \\
& Absolute Error Reduction (\%) & 0.7 & 2.1 & 0.2 & 4.2 \\
\hline
\end{tabular}


The snow model is observed to both over-predict and under-predict energy estimates in an unforeseeable fashion on a monthly, daily, or hourly basis. This is expected behavior, however, since Marion et al. (2013) states that the original model performs well on an annual average despite the fact that "large differences between modeled and measured energy losses should be expected for monthly or shorter time periods" (119). For this reason, results from the model implemented in SAM should only be factored into annual considerations and not applied to monthly or shorter time periods.

\section{One-Axis Tracking Systems}

Sun tracking systems are believed to be much less affected by snow coverage than fixed-tilt systems due to the vibrations and movements of the panels. Nevertheless, the ability to estimate snow losses on tracking systems, however slight they may be, is a recognized need. Because it does not address any potential effects of system movement, Marion's PV snow coverage model was originally only intended for fixed-tilt systems. Preliminary investigations showed that using the snow model as implemented in SAM did still reduce errors for a one-axis tracking system.

Another potentially interesting research question is the effect of nighttime system position on annual energy output. Most single-axis tracking systems are kept in a "stow" position overnight. This means that the rows (Figure 1) are positioned such that average wind loads are minimized; for one single-axis tracking system (Mesa Top) at NREL, this amounts to a nighttime tilt of $5^{\circ}$ to the east. Lower tilt angles inhibit snow removal by sliding, which is likely the only active snow removal process during the night. By instructing the simulation of the Mesa Top system to set the nighttime tilt angle to $20^{\circ}$ instead of $5^{\circ}$, we found that the energy predictions for the simulated system could potentially increase on the order of $1-2 \%$ as a direct result of snow sliding during the night. This suggests that increasing the tilt angle of the nighttime stow position in response to expected snowfall could result in an increase in tracking system energy production. 


\section{National Study}

Following the validation exercises, we applied the snow model to a wide variety of locations in order to estimate typical trends in PV snow coverage losses across the continental United States. In order to accomplish this, we constructed two common system designs in SAM and then used the 1961-1990 NSRDB data set, the underlying historical data used to produce the NSRDB's TMY2 data set. This data set is comprised of hourly meteorological weather data (including daily snow depth measurements) for 239 locations across the United States, spanning the years of 1961 through 1990. For each of the two system types, two simulations were conducted for every year at each location: one without the snow model activated as well as one with the snow model activated, and a percent difference was calculated.

The system designs we used follow the tilt-equals-latitude and tilt-equals- $20^{\circ}$ conventions, both of which are common in the PV industry. In the first case, not only is it thought that setting the tilt angle of a fixed-tilt PV array to the latitude of its location will maximize the total solar radiation over a single year (ignoring shading effects of the surrounding environment), but also, since snowy climates are generally found in the northern areas of the country, the larger tilt angles at these locations are expected to promote quicker snow removal, thereby mitigating the array's losses from snow coverage. On the other hand, system tilts of $20^{\circ}$ are found fairly commonly in the industry due to the simplicity and common availability of this system design. The system of 18 modules was also set to be a single row: 3 modules tall by 6 modules wide. Beyond these settings, all other parameters have been left as the SAM defaults for the detailed photovoltaic/ no financial model in version 2015.6.30. This facilitates replication and avoids listing the many input parameters required by SAM's pvsamv1 compute module. The results of this study are shown in Figure 5, and the tabulated results for each site for each of the two simulations are listed in Appendix A.

As expected, the tilt-equals-latitude systems show lower snow losses than their $20^{\circ}$-tilt counterparts in the continental United States ${ }^{1}$, but for both system designs, the highest PV snow loss is concentrated in an area beginning in the Northeast, spanning the Great Lakes, and continuing into the Midwest and the northern Rocky Mountains. This trend is consistent with the general weather patterns of the regions. However, there are pockets of higher elevation/mountainous areas, even as far south as Arizona, that experience higher snow losses than their nearby neighbors. One such example is Flagstaff, Arizona, which was modeled to experience $3 \%-5 \%$ snow losses depending on the tilt, whereas its nearest neighbor Phoenix, Arizona, was not modeled to experience any snow losses. Note that quite a bit of variation might be expected around these pockets; the more variable the terrain in a given area, the more variable we would expect snow cover to be in that area. The highest annual snow losses seen for both system designs in the continental United States were almost 16\%, located in Minnesota and Michigan. However, three sites in northern Alaska (not shown in Figure 5 but tabulated in Appendix A) experienced higher losses, with the tilt-equals-latitude annual snow loss reaching almost $40 \%$ for one site.

\footnotetext{
${ }^{1}$ This trend is actually not true for multiple systems in Alaska (not shown in Figure 5 but tabulated in Appendix A). We expect that, although the $20^{\circ}$ systems likely suffer a higher percentage of monthly snow loss in the winter months than their tilt-equals-latitude counterparts, the benefit of lower tilt angles during the summer at these high latitudes is enough to overcome this effect when looking at snow loss as a function of annual energy production.
} 
The points in Figure 5 were subsequently used to create maps of general trends in snow losses across the United States for these two system configurations. Figure 6 displays these maps. They can be utilized as a starting point for snow loss estimations of PV systems. For instance, if a $20^{\circ}$ tilt PV system is to be built in Nebraska and a simulation, which does not account for snow, of this system estimated that it would produce $8,000 \mathrm{kWh}$ annually, this figure then indicates that the designer might also want to include a 4\%-7\% loss attributed to snow. It is important to note, however, that these values may not be representative of any particular year nor do they account for any microclimates that might be present. Rather, these values are only meant to represent a starting point for estimating snow losses in a given area before a more specialized analysis can be performed. See Appendix B for larger shareable versions of the maps shown in Figure 6. 

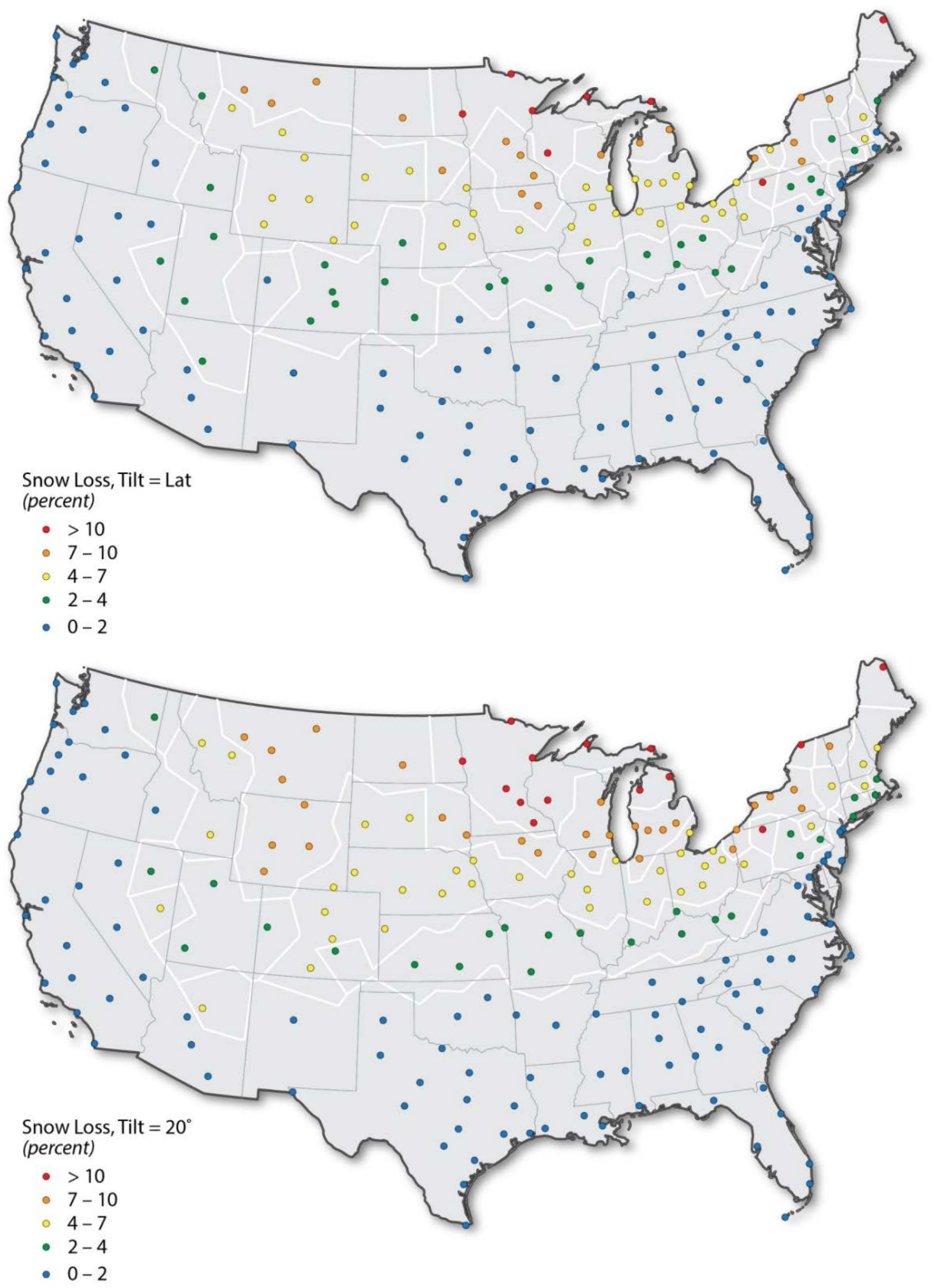

Figure 2. Results from a national study modeling annual average PV production losses due to snow coverage using both a fixed-tilt-equals-latitude and a constant $20^{\circ}$-tilt system design, the historical TMY2 data set, and the newly implemented snow model in SAM

Note: The values displayed at each of the data sites in this study were found by determining, for each individual year and system type, the difference between the results of a simulation without the snow model activated and a simulation with the snow model activated, normalized by the value without the snow model activated. Then an average and standard deviation of these loss percentages were calculated from the 30 years at each of the locations. 

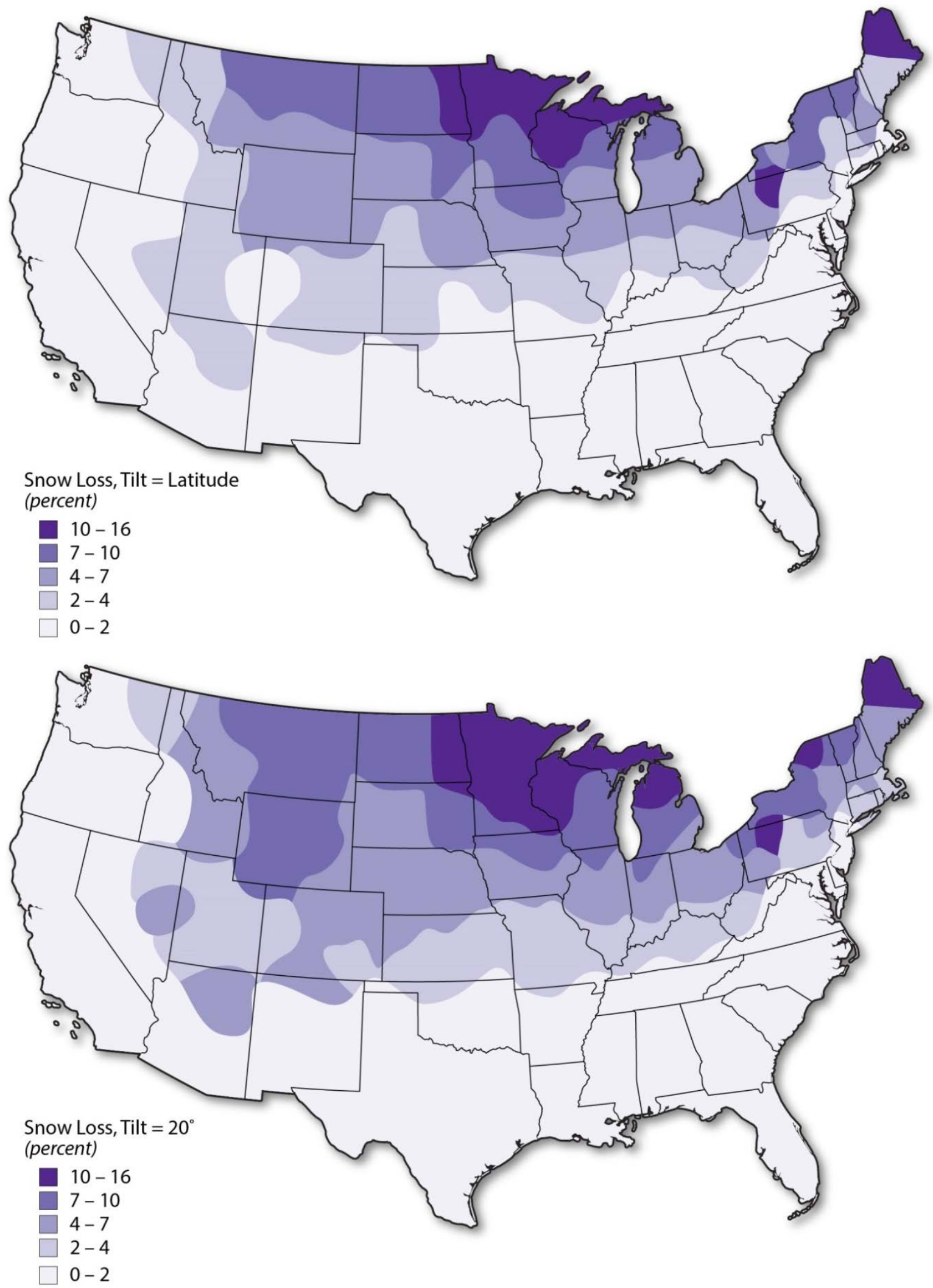

Figure 6. General trends in average snow losses as a percentage of annual energy production. Please see Appendix B for larger, shareable versions of these maps. 
By sorting information based on snow depth rather than geographic location, we were also able to find an interesting correlation between total snow depth throughout a year and the total percent loss resulting from snow coverage for the tilt-equals-latitude system. The results of this are displayed in Figure 7. This figure uses the sum of hourly snow depths, found using

$$
S(h)=\sum_{i=0}^{h} \text { snow_depth }[i]
$$

where $S$ indicates the sum of hourly snow depths, $h$ indicates the hour in the year, and snow_depth $[i]$ refers to the measured snow depth at the $i^{\text {th }}$ hour. This quantity takes into account both the total snow depth throughout the course of a year as well as snow persistence during that year. The percent loss reported for each simulation was calculated in the same manner as it was for Figure 5: by subtracting the result of the simulation with the snow model activated from the result of the simulation without the snow model activated, followed by normalizing this number by the latter. Figure 7 shows a predictable trend in which more snow depth throughout a year corresponds to higher percent loss, showing more of an exponential or polynomial relationship than a linear one. However, Figure 7 also demonstrates clearly that the sum of hourly snow depth is not the only factor affecting the energy loss; as mentioned previously, temperature and planeof-array irradiance also play a role in determining how long panels remain covered. If continuing snow coverage corresponds to low irradiance times, less energy will be lost.

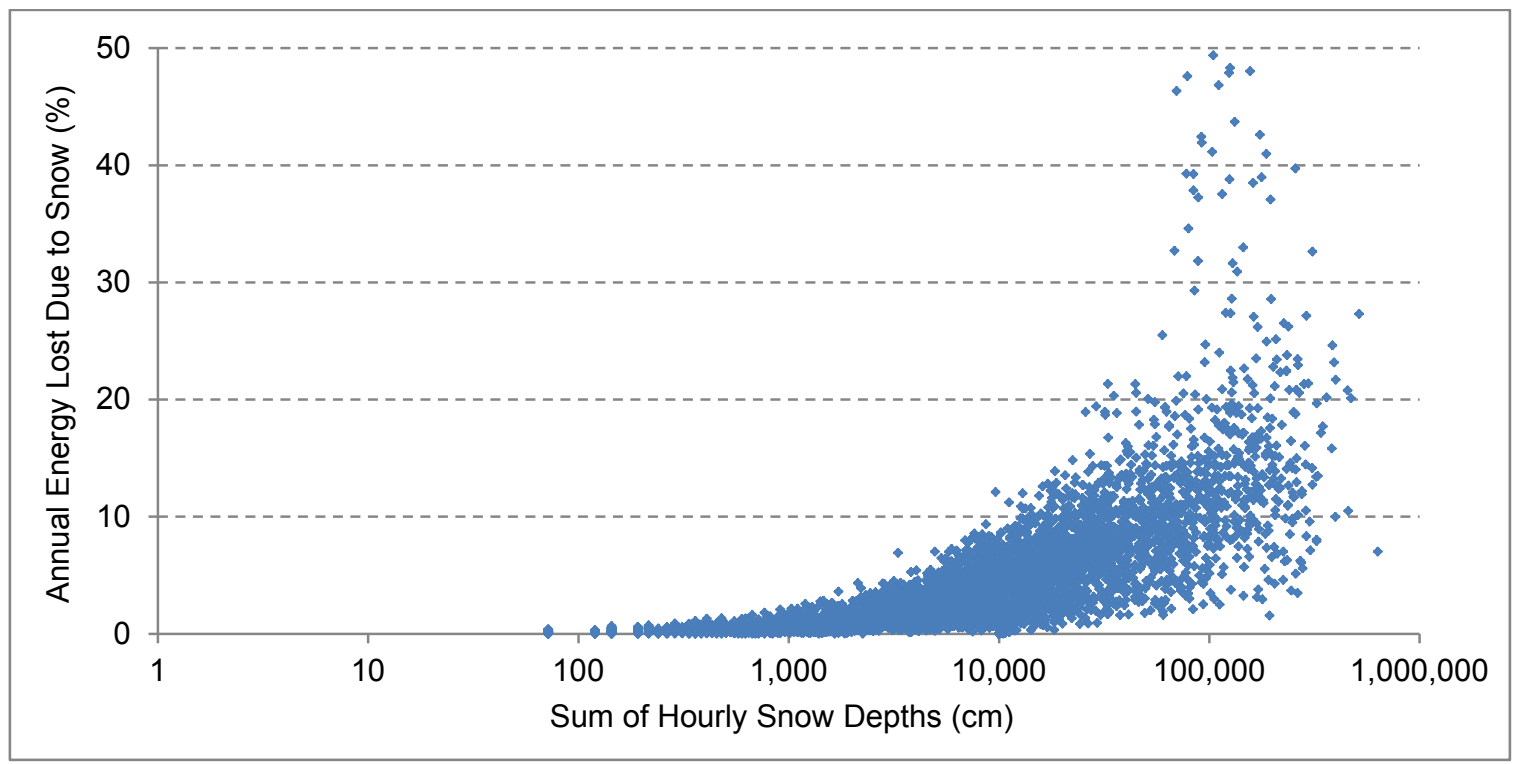

Figure 7. Correlation between the sum of the hourly snow depth array and the resulting percent loss for each year of each location in the tilt-equals-latitude national study 


\section{Conclusions and Future Work}

For several years, the PV community has expressed a need for a reliable model that estimates losses in PV energy production resulting from snow coverage. In an effort to fill this void, we have implemented a snow model into SAM and demonstrated its effectiveness against two fixedtilt systems and a one-axis tracking system, none of which were a part of the model's original development. Subsequently, we conducted a nationwide study to estimate national trends in snow loss percentages to serve as a starting point for more accurate modeling of PV production in snowy areas.

The final implemented PV snow coverage model was kept as similar as possible to Marion's original model (Marion et al. 2013). A few changes were necessary, however, in order to prevent illogical behavior of the model when implemented in SAM, as well as to accommodate for hourly and sub-hourly simulations. We showed that the model could be applied on either the DC or the $\mathrm{AC}$ side of power conversion with very little effect $(<2 \%)$ on the resulting energy estimates. During our validation study, we observed that our implemented model decreased the estimated annual energy error (in comparison to measured values) by over $45 \%$ for the fixed-tilt systems and could potentially reduce error for single-axis tracking systems as well. These represent significant improvements to SAM's performance in snowy conditions and, as a result, we are confident the snow model will provide meaningful snow loss estimations to SAM users. In this analysis, we also postulated that increasing the tilt angles of tracking systems during the night could slightly increase the annual energy production of those systems.

Our national study showed that PV snow coverage losses for fixed-tilt systems ranges from $0 \%$ to $16 \%$ in the continental United States (although some sites in Alaska were as high as 40\%), which is summarized in maps of general estimated snow loss trends across the continental United States for tilt-equals-latitude and $20^{\circ}$-tilt systems. The results from this study can potentially be used as a starting point for future predictions of PV snow losses in these areas. Lastly, we were also able to demonstrate a correlation between total snow depth summed over a year and the percent loss for fixed-tilt, tilt-equals-latitude systems which could also be a good starting point for snow loss estimations if a user has access to snow depth data.

There are certainly areas for improvement in the snow model. It has been shown to improve energy predictions on an annual scale, but the model can both over-predict or under-predict snow losses for any given hour, day, or month. Any effort to reduce these variations will do much to further improve upon the model's accuracy. This could mean incorporating snow removal processes other than sliding, such as melting and wind removal. Another possible improvement would be to investigate whether or not the sliding coefficient discussed in the implementation section is a function of snow consistency or module temperature. Additionally, the model does not account for time-delayed effects, such as a particularly cold night freezing the bottom layer of snow onto a PV array and preventing sliding during the day. Lastly, although we demonstrated the model's efficacy against three independent systems, this model will certainly not always produce reliable results for any PV system in any location. As measured data sets for other systems in snowy areas become available, we hope to continue validation of this snow model with additional systems. 
In the meantime, we hope that this tool will allow the PV community to make more accurate annual energy estimates for systems in all areas of the United States, particularly in the areas which are heavily affected by snow, thereby encouraging more informed technical and financial decisions in the development of future PV systems. 


\section{References}

Marion, B.; Schaefer, R.; Caine, H.; Sanchez, G. (2013). "Measured and modeled photovoltaic system energy losses from snow for Colorado and Wisconsin locations." Solar Energy 97; pp. 112-121.

Becker, G.; Schiebelsberger, B.; Weber, W.; Vodermayer, C.; Zehner, M.; Kummerle, G. (2006). "An approach to the impact of snow on the yield of grid-connected PV systems." Proc. European PVSEC.

Powers, L.; Newmiller, J.; Townsend, W. (2010). "Measuring and modeling the effect of snow on photovoltaic system performance." Presented at Photovoltaic Specialists Conference (PVSC).

Andrews, R.W.; Pollard, A.; Pearce, J.M. (2013). "A new method to determine the effects of hydrodynamic surface coatings on the snow shedding effectiveness of solar photovoltaic modules." Solar Energy Materials and Solar Cells 113; pp. 71-78.

Sugiura, T.; Yamadaa, T.; Nakamuraa, H.; Umeyaa, M.; Sakutab, K.; Kurokawa, K. (2003). "Measurements, analyses and evaluation of residential PV systems by Japanese monitoring program.” Solar Energy Materials and Solar Cells 73(3); pp. 767-779.

Townsend, T.; Powers, L. (2011). "Photovoltaics and snow: An update from two winters of measurements in the sierra." in PVSC.

Andrews, R.W.; Pearce, J.M. (2012). "Prediction of energy effects on photovoltaic systems due to snowfall events." Presented at PVSC.

Freeman, J.; Whitmore, J.; Kaffine, L.; Blair, N.; Dobos, A.P. (2013). "System Advisor Model: Flat plate photovoltaic performance modeling validation report." NREL/TP-6A20-60204. Golden, CO: National Renewable Energy Laboratory. Accessed April 2015: http://www.nrel.gov/docs/fy14osti/60204.pdf.

“National Solar Radiation Data Base: 1961- 1990: Typical Meteorological Year 2.” NSRDB (1995). Accessed March 2015: http://rredc.nrel.gov/solar/old_data/nsrdb/1961-1990/tmy2/. 


\section{Appendix A. Tabulated Results from National Study}

Table A-1. Results from National Study

\begin{tabular}{|c|c|c|c|c|c|}
\hline State & City & $\begin{array}{l}\text { Average Loss } \\
(\%), \text { Tilt }=20^{\circ}\end{array}$ & $\begin{array}{l}\text { Average Loss } \\
\text { (\%), Tilt=Lat }\end{array}$ & $\begin{array}{l}\text { Std Dev Loss } \\
\text { (\%), Tilt=20 }\end{array}$ & $\begin{array}{l}\text { Std Dev Loss } \\
\text { (\%), Tilt=Lat }\end{array}$ \\
\hline AK & Anchorage & 7.1 & 6.6 & 2.6 & 3.0 \\
\hline AK & Annette & 1.3 & 0.9 & 1.0 & 0.8 \\
\hline AK & Barrow & 33.0 & 38.3 & 8.7 & 9.1 \\
\hline AK & Bethel & 14.2 & 14.0 & 5.9 & 6.5 \\
\hline AK & Bettles & 17.3 & 18.1 & 4.0 & 4.9 \\
\hline AK & Big Delta & 12.9 & 15.7 & 3.5 & 4.4 \\
\hline AK & Cold Bay & 7.3 & 6.0 & 2.8 & 2.5 \\
\hline AK & Fairbanks & 12.0 & 14.2 & 3.9 & 4.6 \\
\hline AK & Gulkana & 11.2 & 11.7 & 3.4 & 3.3 \\
\hline AK & King Salmon & 8.9 & 8.2 & 5.0 & 5.0 \\
\hline AK & Kodiak & 3.6 & 2.6 & 1.9 & 1.4 \\
\hline AK & Kotzebue & 19.9 & 20.1 & 6.7 & 7.7 \\
\hline AK & Mcgrath & 14.0 & 15.7 & 4.6 & 5.6 \\
\hline AK & Nome & 15.3 & 12.6 & 6.6 & 5.7 \\
\hline AK & St Paul Is. & 10.2 & 8.7 & 5.2 & 4.3 \\
\hline AK & Talkeetna & 8.9 & 7.6 & 2.7 & 2.7 \\
\hline AK & Yakutat & 6.2 & 4.4 & 2.6 & 2.3 \\
\hline AL & Birmingham & 0.1 & 0.1 & 0.2 & 0.2 \\
\hline AL & Huntsville & 0.4 & 0.3 & 0.5 & 0.4 \\
\hline AL & Mobile & 0.0 & 0.0 & 0.1 & 0.1 \\
\hline$A L$ & Montgomery & 0.0 & 0.0 & 0.1 & 0.1 \\
\hline AR & Fort Smith & 0.6 & 0.4 & 0.6 & 0.4 \\
\hline AR & Little Rock & 0.4 & 0.3 & 0.5 & 0.3 \\
\hline $\mathbf{A Z}$ & Flagstaff & 4.7 & 3.0 & 1.5 & 1.0 \\
\hline$A Z$ & Phoenix & 0.0 & 0.0 & 0.0 & 0.0 \\
\hline $\mathbf{A Z}$ & Prescott & 0.8 & 0.5 & 0.6 & 0.4 \\
\hline$A Z$ & Tucson & 0.0 & 0.0 & 0.1 & 0.1 \\
\hline CA & Arcata & 0.0 & 0.0 & 0.0 & 0.0 \\
\hline CA & Bakersfield & 0.0 & 0.0 & 0.0 & 0.0 \\
\hline CA & Daggett & 0.0 & 0.0 & 0.0 & 0.0 \\
\hline CA & Fresno & 0.0 & 0.0 & 0.0 & 0.0 \\
\hline CA & Los Angeles & 0.0 & 0.0 & 0.0 & 0.0 \\
\hline CA & Sacramento & 0.0 & 0.0 & 0.0 & 0.0 \\
\hline CA & San Diego & 0.0 & 0.0 & 0.0 & 0.0 \\
\hline CA & San Francisco & 0.0 & 0.0 & 0.0 & 0.0 \\
\hline CA & Santa Maria & 0.0 & 0.0 & 0.0 & 0.0 \\
\hline co & Alamosa & 4.4 & 3.0 & 1.7 & 1.3 \\
\hline co & Boulder & 5.5 & 3.9 & 1.4 & 1.2 \\
\hline
\end{tabular}




\begin{tabular}{|c|c|c|c|c|c|}
\hline State & City & $\begin{array}{l}\text { Average Loss } \\
(\%) \text {, Tilt }=20^{\circ}\end{array}$ & $\begin{array}{l}\text { Average Loss } \\
\text { (\%), Tilt=Lat }\end{array}$ & $\begin{array}{l}\text { Std Dev Loss } \\
(\%), \text { Tilt=20 }\end{array}$ & $\begin{array}{l}\text { Std Dev Loss } \\
\text { (\%), Tilt=Lat }\end{array}$ \\
\hline CO & Colorado Springs & 4.3 & 3.4 & 1.7 & 1.4 \\
\hline co & Grand Junction & 2.6 & 1.8 & 1.4 & 1.1 \\
\hline CO & Pueblo & 3.1 & 2.4 & 1.2 & 0.9 \\
\hline CT & Bridgeport & 2.1 & 1.4 & 0.9 & 0.6 \\
\hline CT & Hartford & 3.9 & 2.4 & 1.2 & 0.9 \\
\hline DE & Wilmington & 1.6 & 1.1 & 0.9 & 0.7 \\
\hline FL & Daytona Beach & 0.0 & 0.0 & 0.0 & 0.0 \\
\hline FL & Jacksonville & 0.0 & 0.0 & 0.1 & 0.1 \\
\hline FL & Key West & 0.0 & 0.0 & 0.0 & 0.0 \\
\hline FL & Miami & 0.0 & 0.0 & 0.0 & 0.0 \\
\hline FL & Tallahassee & 0.0 & 0.0 & 0.0 & 0.0 \\
\hline FL & Tampa & 0.0 & 0.0 & 0.0 & 0.0 \\
\hline FL & $\begin{array}{l}\text { West Palm } \\
\text { Beach }\end{array}$ & 0.0 & 0.0 & 0.0 & 0.0 \\
\hline GA & Atlanta & 0.1 & 0.1 & 0.2 & 0.2 \\
\hline GA & Augusta & 0.1 & 0.1 & 0.2 & 0.1 \\
\hline GA & Columbus & 0.0 & 0.0 & 0.1 & 0.1 \\
\hline GA & Macon & 0.1 & 0.0 & 0.1 & 0.1 \\
\hline GA & Savannah & 0.0 & 0.0 & 0.2 & 0.1 \\
\hline HI & Hilo & 0.0 & 0.0 & 0.0 & 0.0 \\
\hline HI & Honolulu & 0.0 & 0.0 & 0.0 & 0.0 \\
\hline HI & Kahului & 0.0 & 0.0 & 0.0 & 0.0 \\
\hline HI & Lihue & 0.0 & 0.0 & 0.0 & 0.0 \\
\hline IA & Des Moines & 6.6 & 5.6 & 2.8 & 2.8 \\
\hline IA & Mason City & 9.5 & 8.6 & 3.2 & 3.2 \\
\hline IA & Sioux City & 6.5 & 5.9 & 2.8 & 2.7 \\
\hline IA & Waterloo & 8.0 & 7.1 & 3.4 & 3.4 \\
\hline ID & Boise & 2.0 & 1.3 & 1.7 & 1.0 \\
\hline ID & Pocatello & 4.6 & 3.6 & 1.7 & 1.6 \\
\hline IL & Chicago & 6.1 & 5.2 & 2.6 & 2.6 \\
\hline IL & Moline & 5.8 & 4.8 & 2.6 & 2.6 \\
\hline IL & Peoria & 5.3 & 4.3 & 2.6 & 2.5 \\
\hline IL & Rockford & 7.2 & 6.0 & 3.3 & 3.2 \\
\hline IL & Springfield & 4.5 & 3.8 & 2.0 & 1.9 \\
\hline IN & Evansville & 2.2 & 1.7 & 1.4 & 1.2 \\
\hline IN & Fort Wayne & 5.8 & 5.0 & 2.1 & 2.0 \\
\hline IN & Indianapolis & 4.3 & 3.5 & 2.2 & 2.0 \\
\hline IN & South Bend & 7.7 & 6.6 & 2.1 & 2.1 \\
\hline KS & Dodge City & 2.7 & 2.1 & 1.2 & 1.0 \\
\hline KS & Goodland & 4.2 & 3.2 & 1.2 & 1.1 \\
\hline KS & Topeka & 3.4 & 2.7 & 1.7 & 1.4 \\
\hline KS & Wichita & 2.2 & 1.8 & 1.2 & 1.1 \\
\hline
\end{tabular}




\begin{tabular}{|c|c|c|c|c|c|}
\hline State & City & $\begin{array}{l}\text { Average Loss } \\
(\%) \text {, Tilt }=20^{\circ}\end{array}$ & $\begin{array}{l}\text { Average Loss } \\
\text { (\%), Tilt=Lat }\end{array}$ & $\begin{array}{l}\text { Std Dev Loss } \\
\text { (\%), Tilt=20 }\end{array}$ & $\begin{array}{l}\text { Std Dev Loss } \\
\text { (\%), Tilt=Lat }\end{array}$ \\
\hline KY & Covington & 3.1 & 2.6 & 1.9 & 1.8 \\
\hline KY & Lexington & 2.4 & 1.9 & 1.4 & 1.2 \\
\hline LA & Baton Rouge & 0.0 & 0.0 & 0.1 & 0.1 \\
\hline LA & Lake Charles & 0.0 & 0.0 & 0.1 & 0.0 \\
\hline LA & New Orleans & 0.0 & 0.0 & 0.1 & 0.1 \\
\hline LA & Shreveport & 0.2 & 0.1 & 0.3 & 0.2 \\
\hline MA & Boston & 2.8 & 1.9 & 1.1 & 0.8 \\
\hline MA & Worchester & 5.9 & 4.1 & 1.9 & 1.4 \\
\hline MD & Baltimore & 1.4 & 0.9 & 0.8 & 0.6 \\
\hline ME & Caribou & 14.4 & 12.2 & 3.0 & 3.1 \\
\hline ME & Portland & 5.6 & 3.5 & 1.6 & 1.1 \\
\hline MI & Alpena & 10.3 & 8.4 & 2.2 & 2.0 \\
\hline MI & Detroit & 5.6 & 4.5 & 1.8 & 1.7 \\
\hline MI & Flint & 7.3 & 5.8 & 1.8 & 1.7 \\
\hline MI & Grand Rapids & 7.4 & 5.9 & 1.8 & 1.6 \\
\hline MI & Houghton & 12.6 & 10.7 & 2.1 & 2.3 \\
\hline MI & Lansing & 7.5 & 6.2 & 1.8 & 1.7 \\
\hline MI & Muskegon & 7.3 & 5.9 & 1.8 & 1.6 \\
\hline MI & Sault Ste. Marie & 15.1 & 13.9 & 2.6 & 2.7 \\
\hline MI & Traverse City & 10.2 & 8.8 & 2.2 & 2.3 \\
\hline MN & Duluth & 15.1 & 13.9 & 3.1 & 3.4 \\
\hline MN & International Falls & 15.9 & 15.5 & 3.8 & 3.8 \\
\hline MN & Minneapolis & 10.7 & 9.5 & 2.9 & 2.6 \\
\hline MN & Rochester & 11.0 & 9.9 & 3.3 & 3.4 \\
\hline MN & Saint Cloud & 11.0 & 9.7 & 3.2 & 3.0 \\
\hline MO & Columbia & 3.7 & 2.9 & 1.6 & 1.5 \\
\hline MO & Kansas City & 3.7 & 3.0 & 1.6 & 1.4 \\
\hline MO & Springfield & 2.3 & 1.8 & 1.1 & 1.0 \\
\hline MO & St. Louis & 3.2 & 2.5 & 1.6 & 1.3 \\
\hline MS & Jackson & 0.1 & 0.1 & 0.3 & 0.2 \\
\hline MS & Meridian & 0.1 & 0.1 & 0.2 & 0.2 \\
\hline MT & Billings & 7.7 & 6.7 & 2.5 & 2.5 \\
\hline MT & Glasgow & 8.7 & 8.3 & 4.0 & 4.1 \\
\hline MT & Great Falls & 7.9 & 7.2 & 2.8 & 2.6 \\
\hline MT & Helena & 6.3 & 5.5 & 2.4 & 2.2 \\
\hline MT & Lewistown & 10.0 & 8.5 & 2.7 & 2.7 \\
\hline MT & Missoula & 4.9 & 4.0 & 1.9 & 1.6 \\
\hline NC & Asheville & 1.0 & 0.6 & 0.6 & 0.4 \\
\hline NC & Cape Hatteras & 0.1 & 0.1 & 0.2 & 0.1 \\
\hline NC & Charlotte & 0.4 & 0.3 & 0.3 & 0.2 \\
\hline NC & Greensboro & 0.7 & 0.4 & 0.5 & 0.3 \\
\hline
\end{tabular}




\begin{tabular}{|c|c|c|c|c|c|}
\hline State & City & $\begin{array}{l}\text { Average Loss } \\
(\%) \text {, Tilt }=20^{\circ}\end{array}$ & $\begin{array}{l}\text { Average Loss } \\
\text { (\%), Tilt=Lat }\end{array}$ & $\begin{array}{l}\text { Std Dev Loss } \\
\text { (\%), Tilt=20 }\end{array}$ & $\begin{array}{l}\text { Std Dev Loss } \\
\text { (\%), Tilt=Lat }\end{array}$ \\
\hline NC & Raleigh & 0.6 & 0.4 & 0.5 & 0.3 \\
\hline NC & Wilmington & 0.2 & 0.1 & 0.3 & 0.2 \\
\hline ND & Bismarck & 9.5 & 8.7 & 3.4 & 3.1 \\
\hline ND & Fargo & 12.2 & 11.7 & 4.0 & 3.9 \\
\hline NE & Grand Island & 5.5 & 4.4 & 2.1 & 1.8 \\
\hline NE & Norfolk & 6.5 & 5.3 & 2.4 & 2.1 \\
\hline NE & North Platte & 4.8 & 3.8 & 1.8 & 1.7 \\
\hline NE & Omaha & 5.8 & 4.7 & 2.4 & 2.0 \\
\hline NE & Scottsbluff & 5.2 & 4.2 & 1.2 & 1.1 \\
\hline NH & Concord & 6.0 & 4.1 & 2.0 & 1.7 \\
\hline NJ & Atlantic City & 1.4 & 1.0 & 0.9 & 0.7 \\
\hline NJ & Newark & 2.0 & 1.2 & 0.9 & 0.7 \\
\hline NM & Albuquerque & 0.8 & 0.6 & 0.5 & 0.4 \\
\hline NV & Elko & 2.9 & 2.0 & 1.6 & 1.1 \\
\hline NV & Ely & 4.3 & 3.0 & 1.6 & 1.2 \\
\hline NV & Las Vegas & 0.0 & 0.0 & 0.1 & 0.1 \\
\hline NV & Reno & 1.5 & 1.0 & 0.8 & 0.6 \\
\hline NV & Tonopah & 0.9 & 0.6 & 0.5 & 0.4 \\
\hline NV & Winnemucca & 1.6 & 1.1 & 1.1 & 0.9 \\
\hline NY & Albany & 5.8 & 3.9 & 1.8 & 1.3 \\
\hline NY & Binghamton & 9.7 & 8.4 & 2.0 & 2.1 \\
\hline NY & Buffalo & 8.6 & 7.4 & 2.0 & 2.0 \\
\hline NY & Massena & 10.7 & 9.8 & 2.7 & 2.6 \\
\hline NY & New York City & 1.9 & 1.2 & 0.9 & 0.6 \\
\hline NY & Rochester & 8.3 & 7.0 & 1.9 & 2.0 \\
\hline NY & Syracuse & 9.1 & 7.5 & 1.7 & 1.8 \\
\hline $\mathrm{OH}$ & Akron & 6.6 & 5.7 & 2.0 & 2.0 \\
\hline $\mathrm{OH}$ & Cleveland & 6.7 & 5.8 & 1.8 & 1.8 \\
\hline $\mathrm{OH}$ & Columbus & 4.1 & 3.6 & 2.0 & 1.9 \\
\hline $\mathrm{OH}$ & Dayton & 4.6 & 3.8 & 2.3 & 2.2 \\
\hline $\mathrm{OH}$ & Mansfield & 6.7 & 5.8 & 1.8 & 1.9 \\
\hline $\mathrm{OH}$ & Toledo & 5.9 & 4.8 & 2.0 & 1.8 \\
\hline $\mathrm{OH}$ & Youngstown & 7.5 & 6.5 & 2.0 & 2.0 \\
\hline OK & Oklahoma City & 1.1 & 0.8 & 0.8 & 0.7 \\
\hline OK & Tulsa & 1.2 & 0.9 & 1.0 & 0.8 \\
\hline OR & Astoria & 0.2 & 0.1 & 0.3 & 0.2 \\
\hline OR & Eugene & 0.3 & 0.2 & 0.5 & 0.4 \\
\hline OR & Medford & 0.2 & 0.1 & 0.3 & 0.2 \\
\hline OR & North Bend & 0.0 & 0.0 & 0.1 & 0.1 \\
\hline OR & Pendleton & 1.6 & 1.5 & 1.2 & 1.2 \\
\hline OR & Portland & 0.2 & 0.2 & 0.3 & 0.2 \\
\hline
\end{tabular}




\begin{tabular}{|c|c|c|c|c|c|}
\hline State & City & $\begin{array}{l}\text { Average Loss } \\
(\%) \text {, Tilt }=20^{\circ}\end{array}$ & $\begin{array}{l}\text { Average Loss } \\
\text { (\%), Tilt=Lat }\end{array}$ & $\begin{array}{l}\text { Std Dev Loss } \\
(\%), \text { Tilt=20 }\end{array}$ & $\begin{array}{l}\text { Std Dev Loss } \\
\text { (\%), Tilt=Lat }\end{array}$ \\
\hline OR & Redmond & 1.7 & 1.4 & 0.7 & 0.7 \\
\hline OR & Salem & 0.3 & 0.2 & 0.4 & 0.3 \\
\hline PA & Allentown & 3.1 & 2.0 & 1.4 & 1.1 \\
\hline PA & Bradford & 11.9 & 10.5 & 1.8 & 2.1 \\
\hline PA & Erie & 7.3 & 6.3 & 1.7 & 1.8 \\
\hline PA & Harrisburg & 2.5 & 1.5 & 1.1 & 0.7 \\
\hline PA & Philadelphia & 1.6 & 1.1 & 0.8 & 0.6 \\
\hline PA & Pittsburgh & 5.6 & 4.8 & 2.0 & 1.9 \\
\hline PA & Wilkes-barre & 5.2 & 3.8 & 1.7 & 1.5 \\
\hline PA & Williamsport & 3.9 & 2.6 & 1.5 & 1.3 \\
\hline PR & San Juan & 0.0 & 0.0 & 0.0 & 0.0 \\
\hline RI & Providence & 2.8 & 1.7 & 0.9 & 0.7 \\
\hline sc & Columbia & 0.1 & 0.1 & 0.2 & 0.2 \\
\hline sc & Greenville & 0.3 & 0.2 & 0.3 & 0.2 \\
\hline SD & Huron & 8.1 & 7.3 & 2.8 & 2.9 \\
\hline SD & Pierre & 6.7 & 5.7 & 2.7 & 2.8 \\
\hline SD & Rapid City & 6.6 & 5.1 & 2.1 & 1.9 \\
\hline SD & Sioux Falls & 8.2 & 6.9 & 3.2 & 3.0 \\
\hline TN & Bristol & 1.6 & 1.2 & 1.0 & 0.8 \\
\hline TN & Chattanooga & 0.3 & 0.2 & 0.3 & 0.2 \\
\hline TN & Knoxville & 0.9 & 0.6 & 0.7 & 0.6 \\
\hline TN & Memphis & 0.5 & 0.4 & 0.6 & 0.5 \\
\hline TN & Nashville & 1.1 & 0.8 & 0.8 & 0.7 \\
\hline TX & Abilene & 0.5 & 0.4 & 0.4 & 0.4 \\
\hline$T X$ & Amarillo & 1.7 & 1.3 & 0.9 & 0.7 \\
\hline TX & Austin & 0.1 & 0.1 & 0.2 & 0.2 \\
\hline TX & Brownsville & 0.0 & 0.0 & 0.0 & 0.0 \\
\hline TX & Corpus Christi & 0.0 & 0.0 & 0.0 & 0.0 \\
\hline TX & El Paso & 0.3 & 0.2 & 0.3 & 0.3 \\
\hline TX & Fort Worth & 0.3 & 0.3 & 0.4 & 0.4 \\
\hline TX & Houston & 0.0 & 0.0 & 0.1 & 0.1 \\
\hline TX & Lubbock & 0.9 & 0.8 & 0.6 & 0.5 \\
\hline TX & Lufkin & 0.1 & 0.1 & 0.2 & 0.2 \\
\hline TX & Port Arthur & 0.0 & 0.0 & 0.1 & 0.0 \\
\hline TX & San Angelo & 0.3 & 0.2 & 0.2 & 0.2 \\
\hline TX & San Antonio & 0.0 & 0.0 & 0.1 & 0.1 \\
\hline TX & Victoria & 0.0 & 0.0 & 0.0 & 0.0 \\
\hline TX & Waco & 0.2 & 0.1 & 0.2 & 0.2 \\
\hline TX & Wichita Falls & 0.6 & 0.5 & 0.5 & 0.4 \\
\hline UT & Cedar City & 3.2 & 2.2 & 1.4 & 1.0 \\
\hline UT & Salt Lake City & 3.5 & 2.3 & 1.4 & 1.1 \\
\hline
\end{tabular}




\begin{tabular}{|c|c|c|c|c|c|}
\hline State & City & $\begin{array}{l}\text { Average Loss } \\
(\%) \text {, Tilt }=20^{\circ}\end{array}$ & $\begin{array}{l}\text { Average Loss } \\
\text { (\%), Tilt=Lat }\end{array}$ & $\begin{array}{l}\text { Std Dev Loss } \\
\text { (\%), Tilt=20 }\end{array}$ & $\begin{array}{l}\text { Std Dev Loss } \\
\text { (\%), Tilt=Lat }\end{array}$ \\
\hline VA & Norfolk & 0.6 & 0.4 & 0.5 & 0.4 \\
\hline VA & Richmond & 1.0 & 0.7 & 0.6 & 0.5 \\
\hline VA & Roanoke & 1.0 & 0.6 & 0.7 & 0.4 \\
\hline VA & Sterling & 1.5 & 1.0 & 0.8 & 0.6 \\
\hline VT & Burlington & 9.3 & 8.0 & 2.9 & 2.9 \\
\hline WA & Olympia & 0.5 & 0.3 & 0.5 & 0.3 \\
\hline WA & Quillayute & 0.5 & 0.3 & 0.5 & 0.4 \\
\hline WA & Seattle & 0.3 & 0.2 & 0.4 & 0.3 \\
\hline WA & Spokane & 3.0 & 2.4 & 1.4 & 1.4 \\
\hline WA & Yakima & 1.5 & 1.1 & 0.9 & 0.7 \\
\hline WI & Eau Claire & 11.4 & 10.3 & 3.1 & 3.4 \\
\hline WI & Green Bay & 9.6 & 8.2 & 2.9 & 2.9 \\
\hline WI & Madison & 8.0 & 6.4 & 2.6 & 2.7 \\
\hline WI & Milwaukee & 7.4 & 6.2 & 2.8 & 2.7 \\
\hline WV & Charleston & 3.4 & 2.8 & 1.5 & 1.3 \\
\hline WV & Huntington & 2.8 & 2.2 & 1.3 & 1.1 \\
\hline WY & Casper & 8.5 & 6.5 & 1.9 & 1.5 \\
\hline WY & Cheyenne & 6.0 & 4.6 & 1.7 & 1.3 \\
\hline WY & Lander & 9.0 & 6.6 & 2.0 & 1.8 \\
\hline WY & Rock Springs & 7.2 & 5.4 & 2.1 & 1.6 \\
\hline WY & Sheridan & 8.6 & 7.0 & 2.1 & 2.2 \\
\hline
\end{tabular}




\section{Appendix B. Full-Size Figures Showing General Trends in Average Snow Losses as a Percentage of Annual Energy Production}

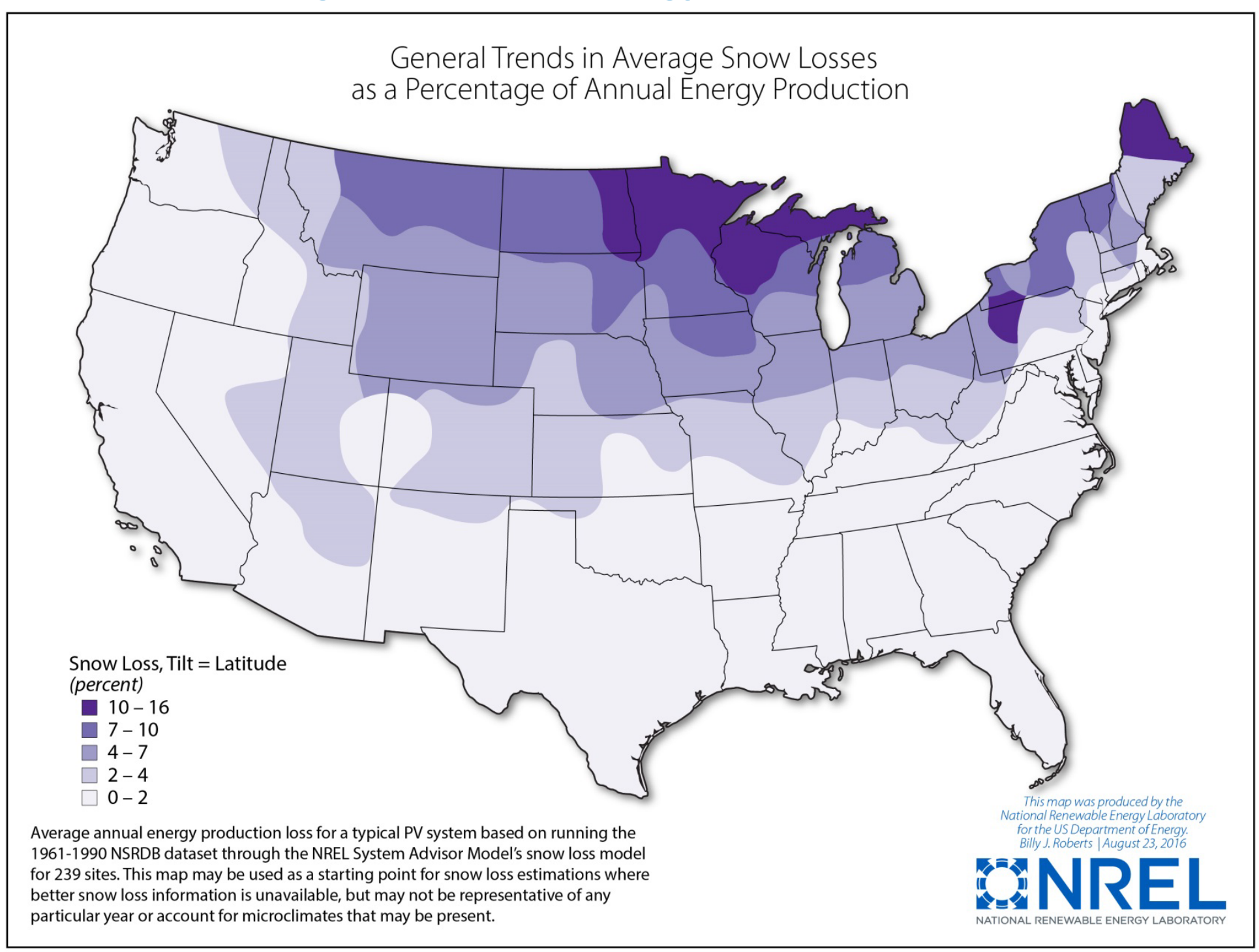




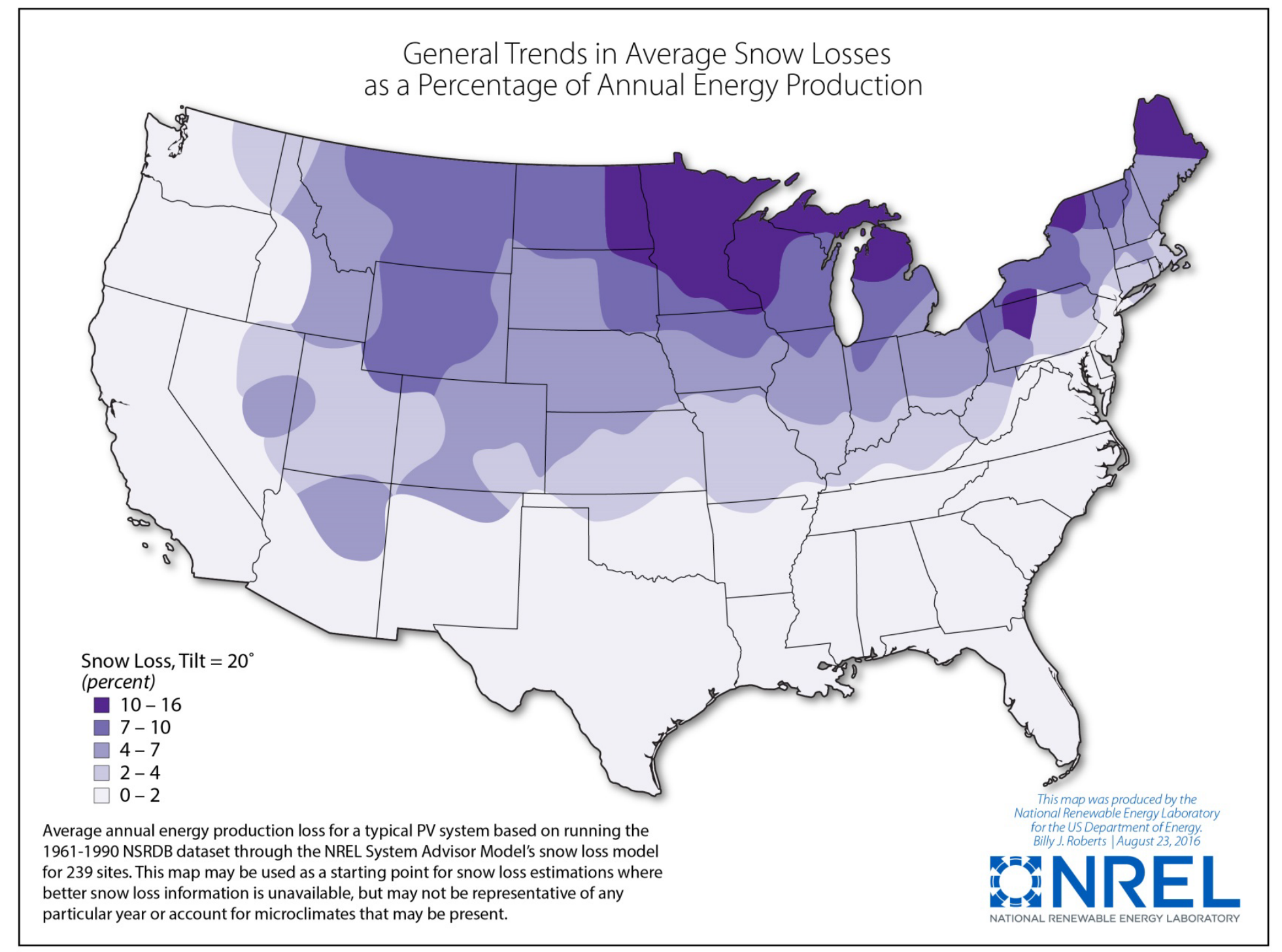

Figure B-1. General trends in average snow losses as a percentage of annual energy production 